\title{
Solvent Control in Electro-Organic Synthesis
}

\author{
Lara Schulz \\ Siegfried R. Waldvogel* (D) \\ Institut für Organische Chemie, Johannes Gutenberg-Universität \\ Mainz, Duesbergweg 10-14, 55128 Mainz, Germany \\ waldvogel@uni-mainz.de
}

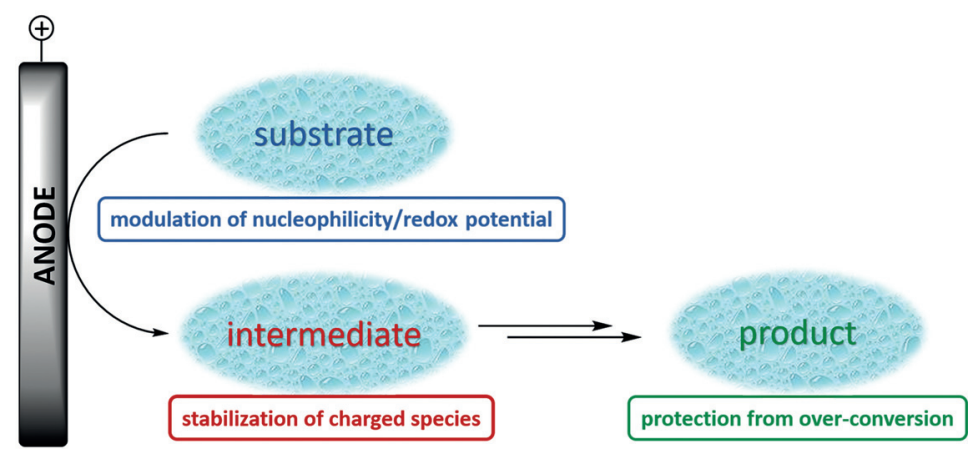

Received: 03.09.2018

Accepted after revision: 17.09 .2018

Published online: 13.12 .2018

DOI: 10.1055/s-0037-1610303; Art ID: st-2018-a0569-a

License terms: cc)

Abstract Exploiting the solvent control within electro-organic conversions is a far underestimated parameter in prep-scale electrolysis. The beneficial application in several transformations is outlined and in particular discussed for the dehydrogenative coupling of arenes and heteroarenes. This simple electrolytic strategy in fluorinated solvents allows the modulation of the substrate's nucleophilicity and the stabilization of the intermediates as well as of the final product from over-oxidation.

1 Introduction

2 Solvent Effects in Kolbe Electrolysis and Anodic Fluorination

3 Unique Solvent Effects of 1,1,1,3,3,3-Hexafluoropropan-2-ol (HFIP)

4 Anodic Dehydrogenative Coupling Reactions with Use of HFIP as the Solvent

5 Conclusion

Key words C-C coupling, electrochemical fluorination, electrosynthesis, Kolbe electrolysis, $\mathrm{N}-\mathrm{C}$ coupling, solvent effect, 1,1,1,3,3,3hexafluoropropan-2-ol

\section{Introduction}

Usually, the electrode material and the applied potential represent the most important parameters in electrochemistry because different reaction courses are often pursued. ${ }^{1}$ However, the electrolysis can only occur at the boundary between electrode and a medium being conductive for the electric current. Such media are called electrolytes and can also influence the reaction pathway in a significant way. ${ }^{2}$ This parameter is often neglected. The electrolytes typically consist of a solvent and a supporting electrolyte to ensure sufficient electric conductivity. In most studies, focus and attention to the nature of the supporting electrolyte is given, because of the ionic charges and the structuring close to the electrode. However, solvents can play a decisive role in the reaction pathways being populated. ${ }^{3}$ Important factors for these solvents are the exploitable potential range, proton activity, dielectric constant, ability to dissolve and dissociate supporting electrolytes, solubility of substrates and intermediates, accessible temperature range, vapor pressure, viscosity, toxicity and, of course, the costs. Solvents for electrochemistry can be divided into two major groups protic and aprotic solvents. Common protic solvents are sulfuric acid, trifluoroacetic acid (TFA), acetic acid, water, methanol (MeOH), 1,1,1,3,3,3-hexafluoropropan-2-ol (HFIP), or ammonia. Except sulfuric acid most of them are not strong electrolytes and therefore supporting electrolytes are required. Examples for the aprotic systems are acetonitrile $(\mathrm{MeCN})$, dimethylformamide (DMF), hexamethylphosphoramide (HMPA), pyridine, dimethyl sulfoxide (DMSO), propylene carbonate (PC), and various ethers. ${ }^{4}$ Nitromethane is also frequently used for anodic oxidative coupling. 5

The used solvent is able to severely affect the reaction outcome as will be outlined in the next paragraphs. For example, nucleophilicity and redox potentials can be distinctly altered by different solvation and intermediates can be solvated more or less and thus, different reaction pathways can be pursued. Furthermore, the product can be protected from over-conversion and the selectivity and yield can be distinctly improved by choosing a suitable solvent system (Figure 1).

\section{Solvent Effects in Kolbe Electrolysis and Anodic Fluorination}

There are several well-known electro-organic syntheses in which the solvent employed has a significant impact on the reaction outcome. ${ }^{6,7}$ Probably, the most famous exam- 


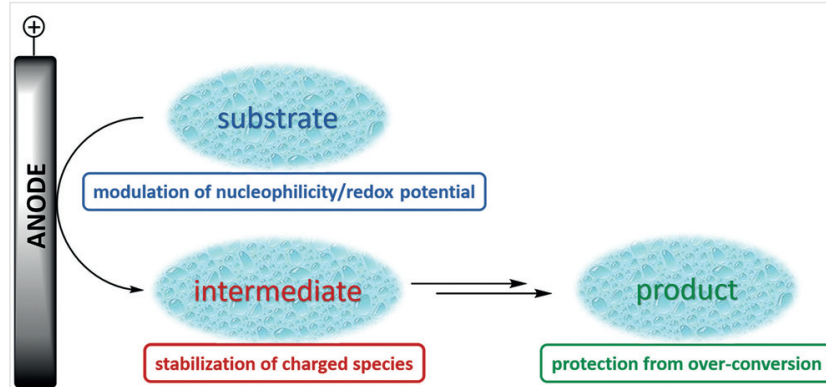

Figure 1 Visualization wherein solvents can influence electrochemical reaction pathways by solvation effects

ple is represented by the oxidation of carboxylic acids, known as Kolbe electrolysis. Usually, aqueous solutions of methanol, DMF, or acetonitrile serve as the solvents. ${ }^{8}$ Best results are commonly obtained when the acid is neutralized by an alkali metal hydroxide or trialkylamine to an extent of $2-5 \%$. Figure 2 schematically displays the impact of different classes of solvents [water $(\mathrm{W})$, protic solvents $(\mathrm{P})$, and dipolar aprotic solvents (DA)] on the formation of two different reactive intermediates (cation $\mathrm{R}^{+}$and radical $\mathrm{R}^{\cdot}$ ) and thus, four typical reaction pathways, which are Kolbe dimerization (blue), substitution (yellow), rearrangement (green), and alkene formation (red). ${ }^{4}$

Kolbe dimerization is favored in acidic, protic solvents as well as in neutral-water and protic-water mixtures, whereas the two-electron non-Kolbe process is preferred in basic and dipolar aprotic solvents. For example, the electrolysis of cyclopropane carboxylic acids leads to different products by using different solvent systems. In a mixture of pyridine $-\mathrm{H}_{2} \mathrm{O}-\mathrm{Et}_{3} \mathrm{~N}$ at the platinum electrodes, the Kolbe

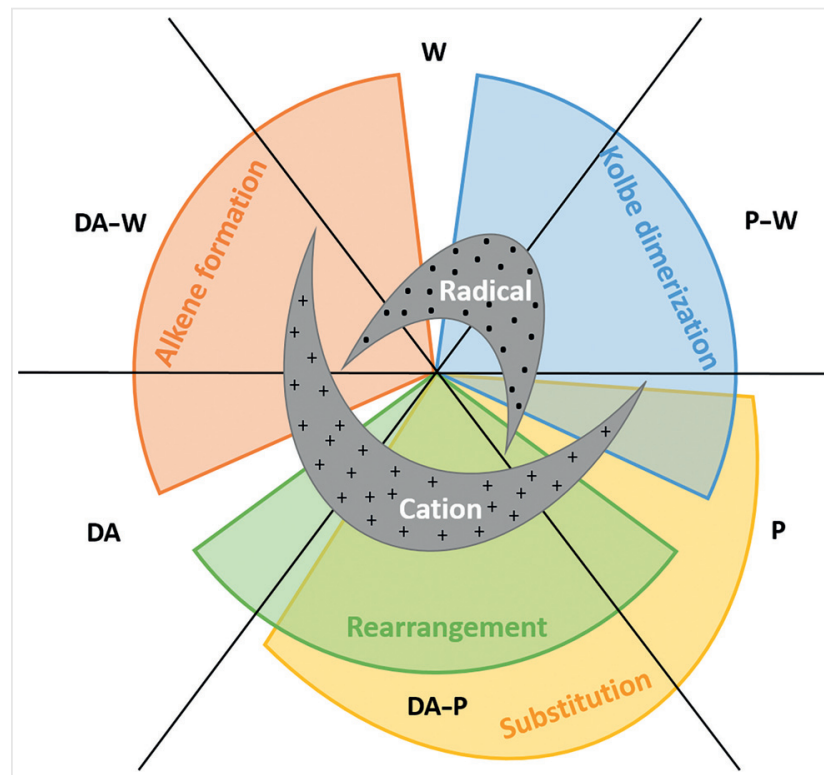

Figure 2 Interrelation between solvent, reactive intermediate, and reaction type. W: water, P: protic solvent, DA: dipolar aprotic solvent such as acetone or DMF

dimer is predominantly formed. However, in a methanolNaOMe solvent mixture, cyclopropane is mainly generated by a hydrogen atom abstraction (Scheme 1$).^{9}$

Another electrochemical synthesis of wide interest, in which the used solvent system can have a severe influence onto the product selectivity, is the anodic fluorination. ${ }^{7}$ Usually, organic solvents such as acetonitrile containing the ionic liquid $\mathrm{Et}_{4} \mathrm{NF} \cdot \mathrm{HF}$ are used for the direct electrochemical fluorination. ${ }^{10}$

\section{Biographical Sketches}

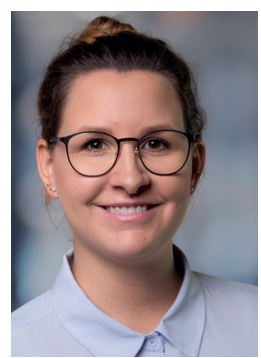

Lara Schulz was born in Frankenthal (Pfalz), Germany in 1991. She studied chemistry at the Johannes Gutenberg Univer- sity Mainz, where she obtained her B.Sc. in 2014 and her M.Sc. in chemistry in 2016. Currently, she is a Ph.D. student under the supervision of Prof. Dr. S. R. Waldvogel, investigating anodic $\mathrm{C}-\mathrm{C}$ cross- and homo-coupling reactions.

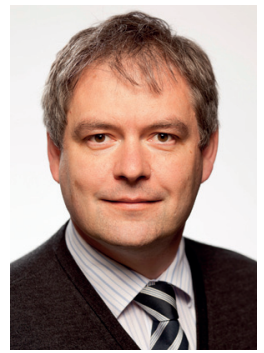

Siegfried R. Waldvogel was born in 1969 in Konstanz, Germany. He studied chemistry at the University of Konstanz and received his Ph.D. in 1996 from the University of Bochum/Max Planck Institute for Coal Research under the supervision of Prof. Dr. M. T. Reetz. After post- doctoral research at the Scripps Research Institute in La Jolla, California (Prof. Dr. J. Rebek, Jr.) he began his habilitation in 1998 at the University of Münster. In 2004, he moved to the University of Bonn as a professor of Organic Chemistry. In 2010, he became full professor at the Johannes Gutenberg University Mainz. His main research interests are dedicated to organic electrochemistry, oxidative coupling reactions with $\mathrm{Mo}^{\mathrm{V}}$ reagents, and supramolecular sensing. 

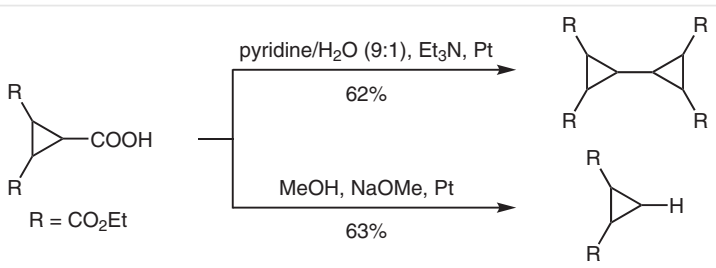

Scheme 1 Solvent effect in Kolbe electrolysis

To avoid the use of flammable organic solvents and circumvent anode passivation as well as side reactions such as acetoamidation, progress has been made by using ionic liquids as the solvent in anodic fluorination reactions. ${ }^{11}$ By using the imidazolium ionic liquid [EMIM][OTf], anodic fluorodesulfurization of 3-phenylthiophthalide was exclusively achieved, whereas in DME, $\alpha$-fluorination proceeded predominantly and desulfurization became the side reaction (Scheme 2). ${ }^{12}$ It is noteworthy, that [EMIM][OTf] seems to destabilize the anodically generated radical cation intermediate similarly to $\mathrm{CH}_{2} \mathrm{Cl}_{2}$ to trigger the desulfurization process.

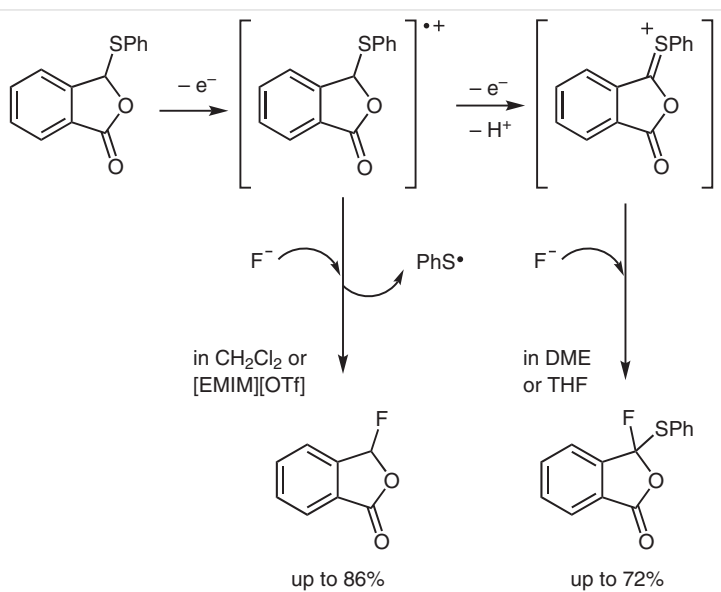

Scheme 2 Solvent effect onto anodic fluorination of 3-phenylsulfanylphthalide

\section{Unique Solvent Effects of 1,1,1,3,3,3- Hexa-fluoropropan-2-ol (HFIP)}

Seminal studies were conducted by the late Eberson, wherein the significantly enhanced stability of the radical cations was observed in 1,1,1,3,3,3-hexafluoropropan-2-ol (HFIP) in comparison to trifluoroacetic acid..$^{13}$ Its beneficial effect is well documented in metal catalysis and oxidation reactions. ${ }^{14,15,16}$ However, no rationale could be given at that time for the exceptional behavior of this solvent. In our group, the outstanding features of HFIP as a solvent in electrochemistry have been utilized since 2009. ${ }^{17}$

Recently, we investigated in close collaboration with Kirchner et al. catalytically active mixtures of HFIP and aqueous $\mathrm{H}_{2} \mathrm{O}_{2}$ by specific molecular dynamics simulations. It was observed that HFIP develops a microheterogeneous structure, which is due to the separation of the hydroxyl groups from the fluorinated alkyl moieties. Thus, large domains are formed which cover significant areas of the system, whereas macroscopically the liquid is still homogeneous. The hydroxyl groups are connected by hydrogen bonding, whereas the fluorine atoms, despite their electronegativity, are not participating in the hydrogen bonding network but cluster together. ${ }^{14}$ Figure 4 displays the segregation of the polar, nonpolar, and fluorous phases of the TEFDDOL (1, Figure 3). ${ }^{18}$

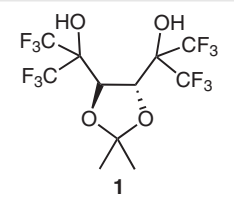

Figure 3 Structure of TEFDDOL (1)

This highly fluorinated analogue of the tartrate-derived TADDOLs ${ }^{19}$ shows the same behavior as HFIP and also exhibits a distinct separation of the three different domains. A long ribbon-kind structure is formed by hydrogen bonding of the hydroxyl groups, which are coated by the fluorous domains, held together by attractive dispersion interaction of the $\mathrm{CF}_{3}$ moieties (Figure 4). ${ }^{16,20}$

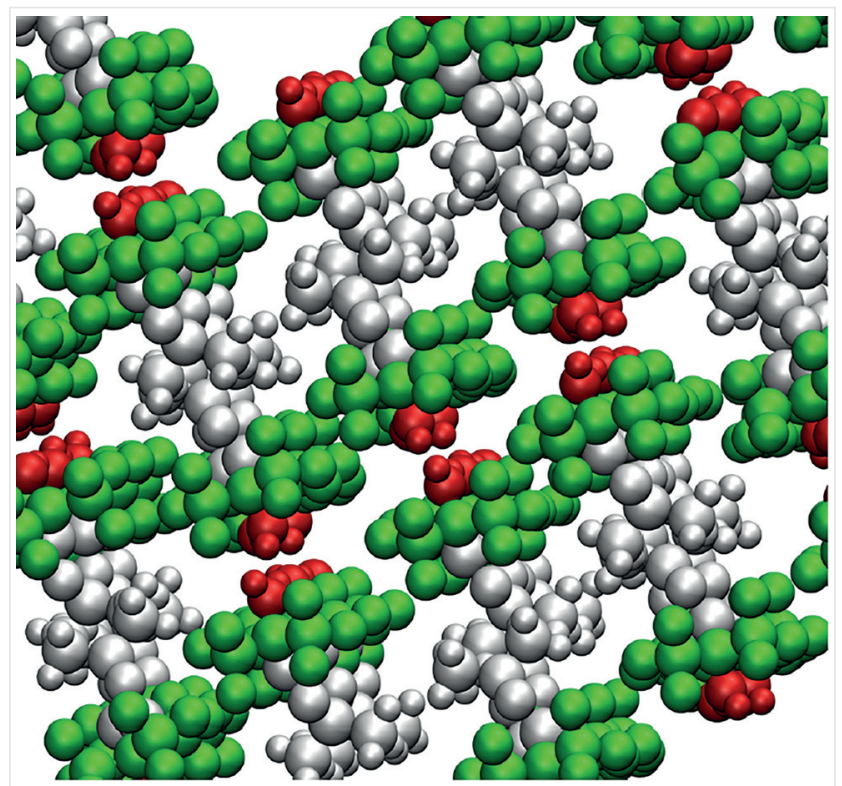

Figure 4 Segregation of polar (hydroxyl groups, red), nonpolar $\left(\mathrm{CH}_{3}\right.$ units and the rings, gray), and fluorous $\left(\mathrm{CF}_{3}-\mathrm{C}_{-}-\mathrm{CF}_{3}\right.$ units, green) phases in the crystal structure of $\mathbf{1}$. Reprinted with permission from ref. 14 . Copyright 2017 American Chemical Society

Radial distribution functions (RDFs) of the hydrogen bonds between the hydrogen bond donor and acceptor molecules in the investigated systems indicate that in pure HFIP, the hydroxyl group acts as a hydrogen bond donor 
and acceptor. As mentioned before, the fluorine atoms are excluded from the hydrogen bonding network and instead, cluster together. Hereby two different domains result, one with fluorous and the other with a polar character. The fluorinated moieties form a continuous microphase, whereas the smaller hydroxyl substituents form small clusters of about 10 hydroxyl groups. If water is added, the number of HFIP-HFIP hydrogen bonds decreases, because water is a stronger hydrogen bonding acceptor than HFIP. Unexpectedly, the water-water interplay exhibits the lowest peak in the RDFs, which means that the occurrence of hydrogen bonds between the water molecules is the merest. This is probably due to the very high hydrogen bonding acceptor feature of HFIP. In consequence of the occupation of the hydrogen bonding acceptor sites of the water, only the HFIP's oxygen atoms are left as acceptors. The fluorous domains show no change in size compared to pure HFIP but the number of individual polar domains decreases, which is due to an increased clustering of the polar groups. Furthermore, the addition of water results in an accelerated movement of the HFIP molecules by a factor of 5 . This finding might be explained by a more flexible hydrogen bonding network in the presence of water. If another component, e.g. a nonpolar hydrocarbon such as cyclooctene, is added to the HFIP/water mixture, the hydrogen bonding network changes once more and the diffusion constants of all components increase. In Figure 5 it is clearly visible that the cyclooctene molecules form small clusters, which are surrounded by the fluorous moieties. ${ }^{14}$ If a polar component such as a phenol or an aniline is added to an HFIP/water mixture instead of a nonpolar one, it is most likely that these polar molecules are also embedded into the hydrogen bonding network and will be part of the polar clusters. Thus, the starting molecules of recently reported anodic $\mathrm{C}-\mathrm{C}$ and $\mathrm{N}-\mathrm{N}$ coupling reactions, radical intermediates, as well as products, formed throughout electrolysis, are to a certain degree protected from over-oxidation, side reactions, and mineralization by these HFIP clusters. As a result, many selective and highly innovative reactions become possible, as outlined in the next paragraphs.

\section{Anodic Dehydrogenative Coupling Reac- tions with Use of HFIP as the Solvent}

Electrochemical dehydrogenative coupling reactions by direct oxidative $\mathrm{C}-\mathrm{H}$ and $\mathrm{N}-\mathrm{H}$ conversion are often challenging because oligomerization or even mineralization of the substrates or the just-built products often occur. In particular, $\mathrm{C}-\mathrm{H} / \mathrm{C}-\mathrm{H}$ cross-couplings of two different arenes are demanding, because one coupling partner has to be selectively oxidized. Without any encouragement, homo- and cross-coupling products will arise statistically without any selectivity. There are many electrochemical approaches to

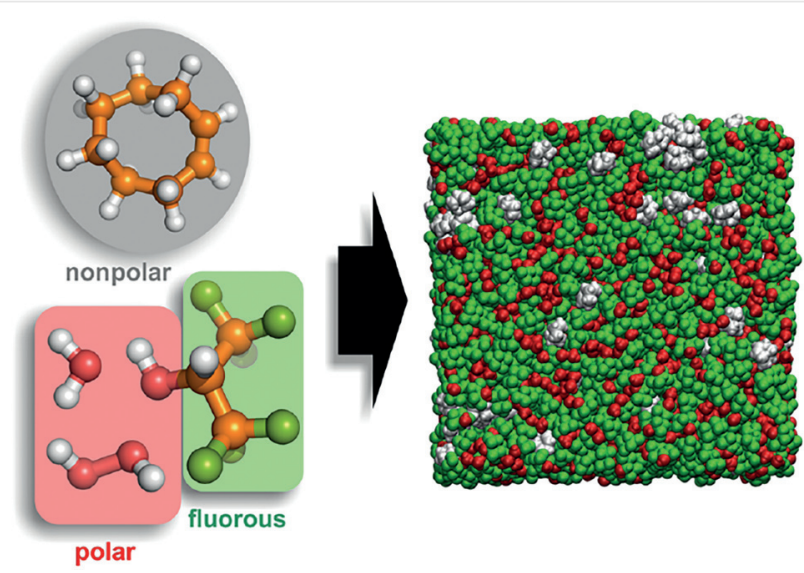

Figure 5 Definition of the subsets that form domains (left) and a snapshot of the simulation box of the HFIP-water $/ \mathrm{H}_{2} \mathrm{O}_{2}$-cyclooctene system with the domain subsets colored accordingly (right). ${ }^{14}$ Reprinted with permission from ref. 14. Copyright 2017 American Chemical Society.

push the reaction in the desired direction, e.g. the extremely elegant "radical cation pool method" by Yoshida and coworkers. ${ }^{21}$ This strategy is based on the separation of the oxidation and the coupling events in time and space to prevent homo-coupling and over-oxidation. However, the need of low temperatures and the exclusive applicability on a small scale $(0.1 \mathrm{mmol})$ make this method less suitable for scalable synthesis. The easiest way to determine the reaction outcome would be the application of an electrolyte system that is able to control the oxidation potential and nucleophilicity of the distinct coupling partners. With HFIP, such a solvent was discovered as the following will show.

In the beginning of investigations regarding the anodic homo-coupling of 2,4-dimethylphenol, a boron-based template strategy was developed. This process can be performed on a multi-kg scale and gave the homo-coupling product in excellent selectivity, but a multi-step sequence is required. ${ }^{22}$ However, the direct electrolysis of 2,4-dimethylphenol is usually challenging because several by-products are formed. Besides the desired biphenol 3, Pummerer's ketone $\mathbf{4}$ is typically the major product and dehydrotrimers with pentacyclic scaffolds (e.g. 5, Scheme 3 ) are obtained in significant amounts. ${ }^{23}$ Testing different electrode materials, Waldvogel et al. surprisingly found that on boron-doped diamond electrodes (BDD) no other by-product than traces of 4 were observed. ${ }^{24}$ BDD electrodes are commonly used for total oxidation and mineralization of organic pollution in waste water, ${ }^{25}$ which makes this finding even more surprising.

An initial screening of additives showed significantly better results in the homo-coupling of 2,4-dimethylphenol when HFIP was used as an additive. Other primary alcohols with fluorous moieties in the $\beta$ position, such as $2,2,3,3$ tetrafluoropropanol, 2,2,2-trifluoroethanol, or 2,2,3,3,4,4,5,5-octafluoropentanol could also be applied but gave minor yields compared to HFIP. Trifluoroacetic acid 


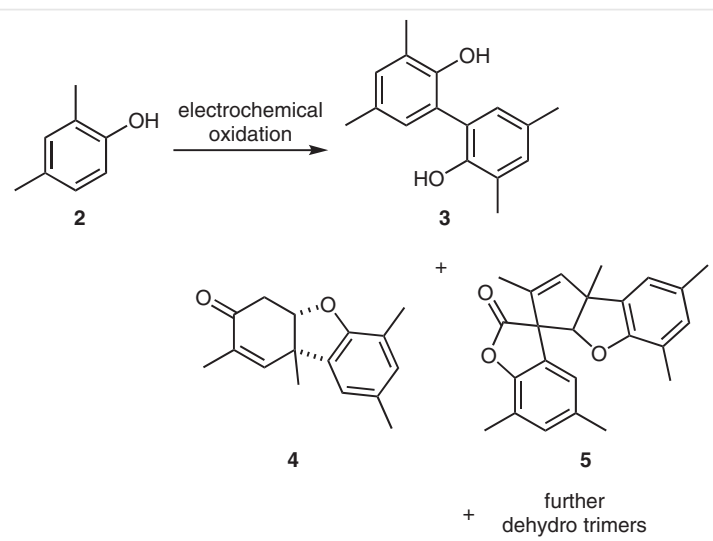

Scheme 3 Product diversity (major components) from the electrochemical oxidation of 2,4-dimethylphenol 2

and the respective carboxamide gave significantly inferior results, revealing that the Brønsted behavior of HFIP is not the reason for the good conversion of 2,4-dimethylphenol. ${ }^{17}$ The application of the optimized parameters for the homocoupling of 2,4-dimethylphenol could be extended to guaiacol derivatives. By serendipity, it was found that 4methylguaiacol (6) gave the nonsymmetric ortho-meta coupled biphenol $\mathbf{7}$ after electrolysis as the sole product (Scheme 4). This led to the assumption that the biphenol products are not generated by radical recombination because otherwise, only symmetric biphenols would be formed. Thus, an oxidation of the phenol followed by a nucleophilic attack of another phenol and a subsequent second oxidation step is more likely (cf. mechanistic rationale, Scheme 5).

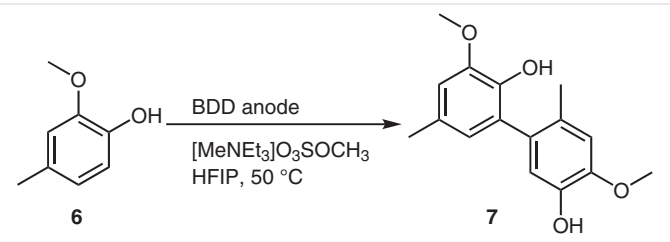

Scheme 4 Electrochemical oxidation of 4-methylguaiacol (6) on BDD in HFIP gives the nonsymmetric ortho-meta coupled product, which represents the first anodic phenol-phenol cross-coupling reaction in HFIP.

Anodic treatment of other guaiacol derivatives led to the finding that, depending on the steric demand of the substituent in position 4 , either a symmetric or nonsymmetrical biphenol was obtained. ${ }^{26}$ After this lucky finding, the idea arose to extend this exceptional synthesis to various phenol-phenol cross-couplings as well as phenolarene cross-coupling reactions. ${ }^{27}$ In general, it was observed that the addition of HFIP significantly reduces the oxidative degradation of the substrates and products.

Throughout the investigations considering HFIP-based electrolytes for electrochemical double layer capacitors, studies on the electrochemical stability of HFIP were con- ducted. Cyclic voltammetry experiments with HFIP as the solvent and tetrabutylammonium perchlorate (TBAPC) as supporting electrolyte showed an excellent stability of the electrolyte (see Table 1 ). ${ }^{28}$ Since the solvent contains active protons, the ideally polarizable regime is limited on platinum because of the onset of hydrogen evolution at $+0.25 \mathrm{~V}$ vs. $\mathrm{Ag} / \mathrm{AgCl}$ (Table 1, black line). However, the cathodic limit on glassy carbon is distinctly increased towards more negative values because of the high overpotential of glassy carbon towards the reduction of protons (red line). This results in a potential window of $4.6 \mathrm{~V}$, which is remarkable for an alcohol and is comparable to aprotic solvents with the same supporting salt. ${ }^{28}$

Table 1 Cyclic Voltammograms of 0.1 M HFIP-Based Electrolytes Measured on Glassy Carbon and Pt Electrodes; Scan Rate: $10 \mathrm{mVs}^{-1}$; RE: $\mathrm{Ag} / \mathrm{AgCl}$ in sat. LiCl/EtOH. ${ }^{28}$ Reprinted from ref. 28, with Permission from Elsevier.

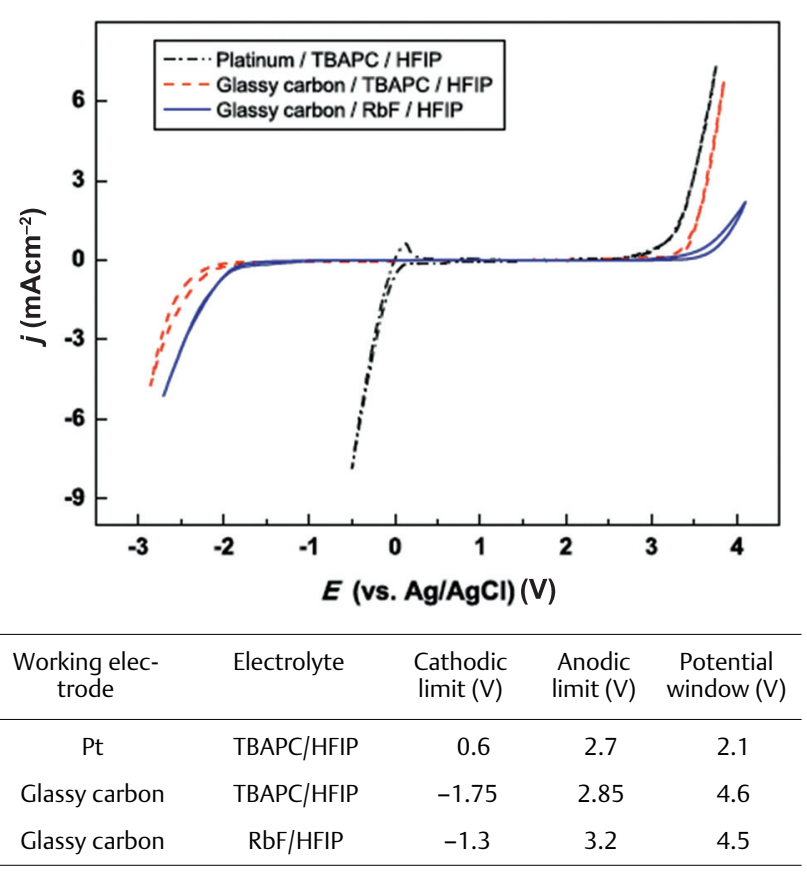

Because of its extraordinary stability, HFIP can almost quantitatively be recycled and reused after electrolysis. ${ }^{29}$ Exactly this recycling of HFIP led Waldvogel et al. to another important finding - the beneficial role of protic additives such as water or methanol. In the beginning, phenol-arene cross-coupling reactions were carried out in highly pure HFIP. In this case, the desired cross-coupling product 8ab was only formed as a minor product. The major side reaction was the undesired formation of homo-coupling product $\mathbf{8 b b}$ (Table 2, entry 1). By using recycled HFIP, the yield of the cross-coupling product as well as the selectivity improved distinctly. ${ }^{1} \mathrm{H}$ NMR data of such recycled HFIP indicated traces of water and methanol; thus a systematic study 
with different amounts of these additives in the electrolyte was conducted (Table 2, entries 2-12). For easier work-up on a preparative scale, $8 \mathbf{a b}$ was acylated. ${ }^{30}$

Table 2 Influence of Protic Additives onto Anodic Phenol-Arene Cross-Coupling Reaction. ${ }^{\mathrm{a}, 30}$ Adapted with Permission from ref. 30. Copyright 2012 American Chemical Society.

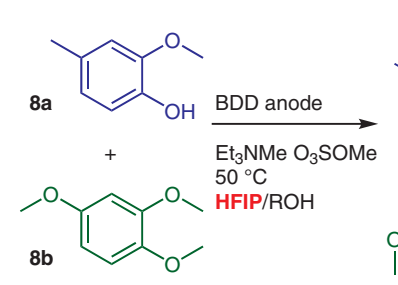<smiles>COc1cc(OC)c(-c2cc(-c3cc(OC)c(OC)cc3OC)c(OC)cc2OC)cc1OC</smiles>
8c: $\mathrm{R}=\mathrm{CH}_{3}$
8d: $\mathrm{R}=\mathrm{C}_{2} \mathrm{H}_{6}$

\begin{tabular}{|c|c|c|c|c|}
\hline Entry & $\begin{array}{l}\text { Ratio } \\
\mathbf{8 a} / \mathbf{8 b}\end{array}$ & $\begin{array}{l}\mathrm{HFIP} / \mathrm{ROH} \\
(\mathrm{mL} / \mathrm{mL})\end{array}$ & $\begin{array}{l}\text { Yield } \\
(\%)^{\mathrm{b}}\end{array}$ & $\begin{array}{l}\text { Ratio } \\
\mathbf{8} \mathbf{a b} / \mathbf{8} \mathbf{b b}^{\mathrm{c}}\end{array}$ \\
\hline 1 & $1: 5$ & $30-$ & $21(8 d)$ & $1: 3$ \\
\hline 2 & $1: 5$ & $32 / 1\left(\mathrm{H}_{2} \mathrm{O}\right)$ & $47(8 d)$ & $1.5: 1$ \\
\hline 3 & $1: 5$ & $31 / 2\left(\mathrm{H}_{2} \mathrm{O}\right)$ & $68(8 d)$ & $8: 1$ \\
\hline 4 & $1: 5$ & $30 / 3\left(\mathrm{H}_{2} \mathrm{O}\right)$ & $67(8 d)$ & $85: 1$ \\
\hline 5 & $1: 5$ & $28 / 5\left(\mathrm{H}_{2} \mathrm{O}\right)$ & $41(8 d)$ & $>100: 1^{d}$ \\
\hline 6 & $1: 5$ & 31/2 (MeOH) & $56(8 d)$ & $2: 1$ \\
\hline 7 & $1: 5$ & $31 / 2(\mathrm{MeOH})$ & $66(8 c)$ & $6: 1$ \\
\hline 8 & $1: 5$ & $31 / 2(\mathrm{MeOH})$ & $64(8 d)$ & $11: 1$ \\
\hline 9 & $1: 5$ & $31 / 2(\mathrm{MeOH})$ & $66(8 d)$ & 10:1 \\
\hline 10 & $1: 5$ & 31/2 (MeOH) & $69(8 d)$ & $90: 1$ \\
\hline 11 & $1: 5$ & 31/2 (MeOH) & $55(\mathbf{8 d})$ & 22:1 \\
\hline 12 & $1: 7$ & 31/2 (MeOH) & $58(8 d)$ & $45: 1$ \\
\hline 13 & $1: 3$ & 31/2 (MeOH) & $69(8 d)$ & $>100: 1^{d}$ \\
\hline 14 & $1: 2$ & 31/2 (MeOH) & $55(8 d)$ & $45: 1$ \\
\hline
\end{tabular}

a Electrolytic conditions: $50^{\circ} \mathrm{C}$, constant current $\left(j=2.8 \mathrm{~mA} / \mathrm{cm}^{2}\right)$, BDD anode, nickel cathode, undivided cell, $2 \mathrm{~F} / \mathrm{mol}$ (ref. phenol), $0.68 \mathrm{~g} \mathrm{Et}_{3} \mathrm{NMe} \mathrm{O}_{3} \mathrm{SOMe}$.

${ }^{\mathrm{b}}$ Isolated yield of homo-coupling product.

' Determined by GC.

${ }^{\mathrm{d}}$ Homo-coupling product $\mathbf{8 b b}$ was not detected.

Distinctly superior results could be obtained by using $9 \mathrm{vol} \% \mathrm{H}_{2} \mathrm{O}$ and $18 \mathrm{vol} \% \mathrm{MeOH}$, respectively. It is noteworthy, that this corresponds to the same molar amount of additive. The yield could be increased to $67 \%$ and the selectivity increased to $85: 1\left(9 \mathrm{vol} \% \mathrm{H}_{2} \mathrm{O}\right.$, entry 4$)$. Even better results were obtained by the addition of $18 \mathrm{vol} \% \mathrm{MeOH}$; the desired cross-coupling product was obtained in $69 \%$ yield and a slightly better selectivity of 90:1 (entry 10). Further improvements were made by varying the excess of the arene compound from 5 to 7, 3, and 2 equivalents, respectively (entries 12,13, and 14). Best results were obtained by using a molar ratio $\mathbf{8 a} / \mathbf{8 b}=1: 3$ (entry 13 ) and the crosscoupling product could be isolated in $69 \%$ yield with exclusive selectivity. Furthermore, the oligomerization during electrolysis was decreased. These optimized reaction conditions set the stage for a broad variety of phenol-arene couplings. In all examples studied, the selectivity was clearly enhanced and the yield was often increased. In addition, the scope was extended because several new biaryls could be accessed. ${ }^{30}$

Driven by curiosity why no homo-coupling product 8aa was observed after electrolysis, the reaction of 4-methylguaiacol 8a with trimethoxybenzene $\mathbf{8 b}$ was further investigated. ${ }^{31}$ When two aromatic components $\mathbf{A}$ and $\mathbf{B}$ are directly electrolyzed, the expected major products are the respective cross-coupling products $\mathbf{A} \mathbf{A}$ and $\mathbf{B B}$ because the reaction outcome is determined by the electron density and therefore the nucleophilicity of the individual substrates. The compound with a higher electron density exhibits a lower oxidation potential and should therefore be preferentially oxidized at the anode. Electron density and nucleophilicity are directly linked, thus the same compound will enter the reaction sequence for a nucleophilic attack. This way, only homo-coupling products would be expected. Surprisingly, in the electrolysis of 4-methylguaiacol 8a and trimethoxybenzene $\mathbf{8 b}$ no homo-coupling of component $\mathbf{8 a}$
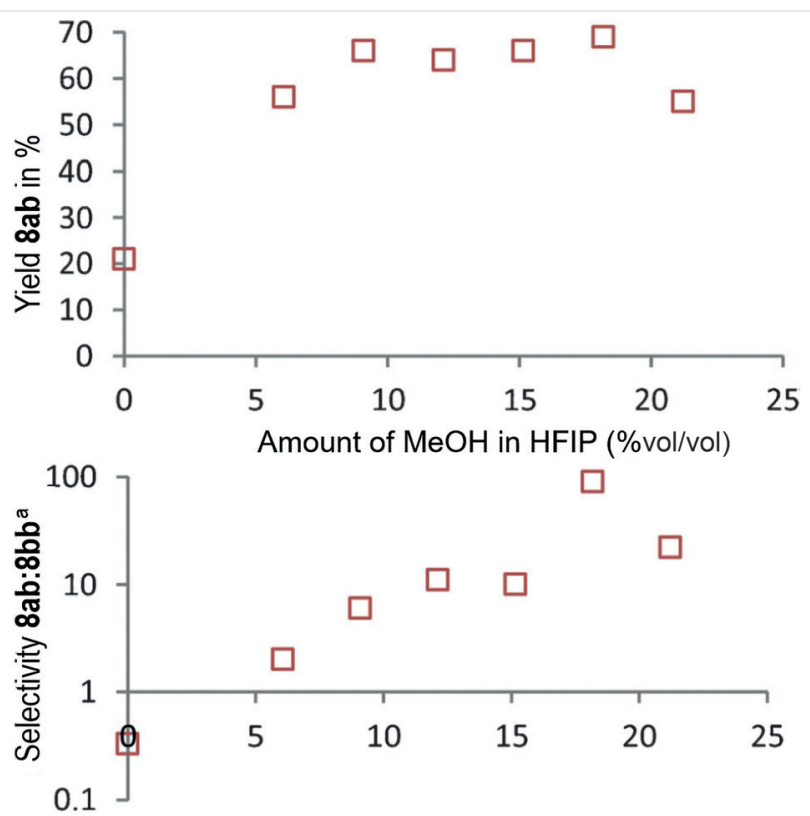

Amount of $\mathrm{MeOH}$ in HFIP (\%vol/vol)

Figure 6 Yield and selectivity of $\mathbf{8 a b}$ formed as a function of the amount of $\mathrm{MeOH}$ in HFIP. a Selectivity was determined by gas chromatopgraphy. ${ }^{31}$ Adapted from ref. 31, with permission from John Wiley and Sons. 
occurred. Instead, the cross-coupling product 8ab and the homo-coupling product 8bb were obtained, but almost without selectivity. By adding different amounts of $\mathrm{MeOH}$ to the electrolyte, the reaction outcome could drastically be changed (Figure 6).

The addition of methanol not just improved 8ab's yield distinctly but also enhanced the selectivity regarding the cross-coupling product immensely. Best results were obtained by using $18 \mathrm{vol} \% \mathrm{MeOH}$ in HFIP, and 8ab was obtained in $69 \%$ yield and exclusive selectivity. To find an explanation for these unusual findings, cyclic voltammetry experiments were conducted. These investigations indicated a clear shift of oxidation potentials in HFIP when $\mathrm{MeOH}$ is added to the electrolyte (Figure 7). In pure HFIP, 8b exhibits a lower oxidation potential and should be preferentially oxidized at the anode, which is consistent with the preparative electrolysis. By addition of methanol, the oxidation potential of $\mathbf{8 b}$ subsequently increases while 8a's potential decreases. This engenders a reversal of the oxidation potentials - 8a now exhibits the lower oxidation potential. Nevertheless, even at $18 \mathrm{vol} \% \mathrm{MeOH}$ in the electrolyte, no homo-coupling of component 8a was observed, clearly indicating that the used solvent system must also influence the nucleophilicity of the employed substrates.

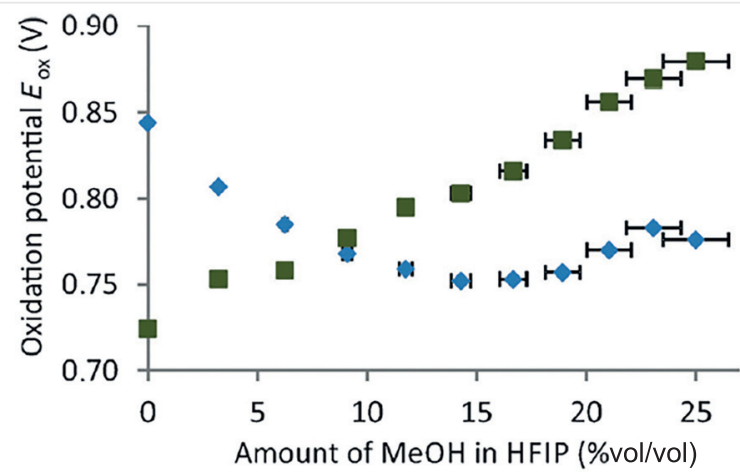

Figure 7 Shift of oxidation potentials with increasing amount of $\mathrm{MeOH}$ in HFIP. Blue diamonds: 8a, green squares: 8 b. WE: glassy carbon electrode tip, $2 \mathrm{~mm}$ diameter; CE: glassy carbon rod; $\mathrm{RE}: \mathrm{Ag} / \mathrm{AgCl}$ in sat. LiCl/EtOH. Solvent: HFIP + 0-25 vol\% MeOH. Criteria for oxidation: $j=$ $0.1 \mathrm{~mA} / \mathrm{cm}^{2} ; v=50 \mathrm{mV} / \mathrm{s} ; T=20^{\circ} \mathrm{C}$. Stirring conditions during measurement. c(substrate) $=151 \mathrm{~mm}$; supporting electrolyte: $0.09 \mathrm{M} \mathrm{Bu}_{3} \mathrm{NMe}$ $\mathrm{O}_{3}$ SOMe. ${ }^{31}$ Reprinted from ref. 31 , with permission from John Wiley and Sons.

According to our proposed mechanism, component 8a is, after shifting the oxidation potentials, selectively oxidized at the anode to give phenoxyl radicals (step I, Scheme 5). Now, the solvent system prevents the nucleophilic attack of the same component in step II and thus, inhibits formation of the phenol homo-coupling product. Instead, arene component $\mathbf{8 b}$ enters the reaction sequence to form the intermediate which gives, after a second oxidation step (step III) and aromatization, the desired cross-coupling product 8ab. Needless to say that the following question came up: How is the solvent system able to keep phenol 8a off from entering the reaction sequence in step II to form the homo-coupling product?

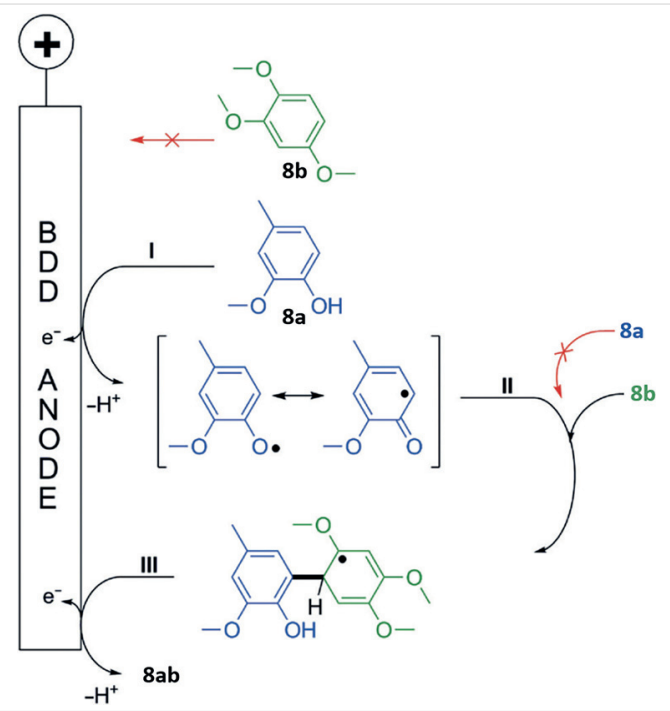

Scheme 5 Proposed mechanism for the anodic phenol-arene crosscoupling with 18 vol\% MeOH in HFIP. ${ }^{31}$ Adapted from ref. 31, with permission from John Wiley and Sons.

A possible explanation is that in polar solvents such as HFIP, phenols are stronger solvated than arenes. This applies not only to phenols but also to every substrate that is able to participate in the hydrogen bonding network mentioned before, e.g. anilides. In the present case, 1,2,4-trimethoxybenzene (B, Scheme 7) exhibits a lower oxidation potential in pure HFIP and is therefore oxidized at the anode. Because of its strong solvation, 4-methylguaiacol (A, Scheme 7) is strongly shielded by HFIP, which prevents nucleophilic attack on the radical cation of the arene. Thus, the more electron-rich arene undergoes homo-coupling. Added methanol acts like a weak base when added to the electrolyte and weakens the solvate of the phenol and simultaneously facilitates its deprotonation by interacting through hydrogen bonding. Because of the shifted potentials, phenol $\mathbf{A}$ is now oxidized at the anode and the lessshielded arene can start a nucleophilic attack - the crosscoupling product $\mathbf{B}$ is selectively formed. Thus, a decoupling of the oxidation potential from the nucleophilicity is achieved by using this unique electrolyte. ${ }^{31}$

Since then, many different substance classes could be utilized in the direct anodic cross-coupling reaction. By using this simple electrolysis protocol, many different product classes became easily accessible because no leaving functionalities or additional oxidizers are needed. Thus, many synthetic steps for preparing starting materials or a timeand wasteful work-up become superfluous. Furthermore, the shown anodic transformations are inherently safe and easily scalable with similar yield and selectivity. ${ }^{32,33}$ There- 
fore, the presented electrosyntheses are definitely technically relevant. ${ }^{34}$ For example, partially protected biphenols, which formerly had to be synthesized in a multi-step process, are now accessible through a one-pot electrosynthesis (Scheme 6). ${ }^{32}$

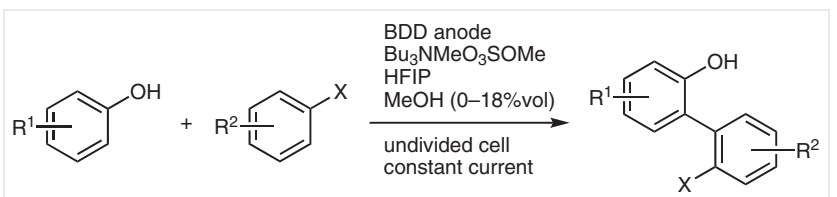

$$
\mathrm{X}=\mathrm{OH} \text {, OTIPs }
$$$$
\text { up to } 92 \%
$$<smiles>COc1cc(C)cc(-c2c(O)c(C(=O)O)cc3ccccc23)c1O</smiles>

$82 \%$<smiles>COc1cc(-c2ccc(C(C)(C)C)cc2O)c(O)c(C(C)(C)C)c1</smiles>

$92 \%$<smiles>COc1cc(-c2cc3c(cc2O)OCO3)c(O)c(C(C)(C)C)c1</smiles>

$82 \%$
Scheme 6 Anodic formation of nonsymmetric biphenols and nonsymmetric, partially protected biphenols ${ }^{32,35}$

Moreover, many aniline derivatives could be applied in various cross- and homo-coupling reactions to form valuable 2,2'-diaminobiaryls, which are hardly available in classic organic synthesis because of the anilines' predisposition for polymerization. ${ }^{36-38}$ Besides the already mentioned phenol-arene ${ }^{27,30}$ and phenol-phenol ${ }^{39}$ cross-couplings, a broad variety of biphenols could be synthesized (Scheme 6). ${ }^{32,35}$ Comparison of the electrochemical approach with the same products synthesized by using chemical oxidizers demonstrated that the developed electrochemical protocol can easily compete with conventional methods. ${ }^{35}$ Another improvement in the phenol-phenol cross-coupling could be achieved by installing a TIPS group in one of the substrates. This strategy allows the construction of partially protected biphenols, which formerly had to be synthesized in an effortful multi-step process. Moreover, the cross-coupling yield was distinctly improved. A possible explanation is the twist of the partially protected biphenol because of the bulky TIPS group and thus better stabilization by solvation in HFIP that protects the just-built product from overoxidation. ${ }^{32}$ Additionally, the solvation features of this outstanding solvent system allow the electrosyntheses to be conducted at high as well as at lower current densities, just as needed. Several of the $\mathrm{C}-\mathrm{C}$ cross-coupling reactions performed by using this technique showed an unexpected high robustness towards high current densities, which could be altered in the range of two orders of magnitude without decreasing selectivity or product yield. This extraordinary effect is yet unknown for electrochemical synthesis of products with similar oxidation potentials as the starting materials. ${ }^{40}$

Figure 8 shows three representative cross-coupling products, which could be synthesized by using a current density of $j=7.2 \mathrm{~mA} / \mathrm{cm}^{2}$ and $j=35 \mathrm{~mA} / \mathrm{cm}^{2}$. In the case of the $m$-terphenyl-2,2"-diol, the yield was even increased from 28 to $58 \%$ by using a higher current density.

Recent studies extended the applicability of this process to the electrochemical synthesis of protected symmetric and nonsymmetric bianiline derivatives, ${ }^{36,37} \mathrm{~N}, \mathrm{O}$-biaryl structures and biaryl ethers by coupling reactions of naphthylamines with phenols ${ }^{41}$ (Scheme 8), (2-hydroxyphenyl)benzofurans, ${ }^{43} \mathrm{~m}$-terphenyl-2,2"-diols by two-fold C-C cross-coupling, ${ }^{42}$ and the single and two-fold $\mathrm{C}-\mathrm{C}$ crosscoupling of phenols with thiophenes (Scheme 9) and benzothiophenes. $^{33,44}$

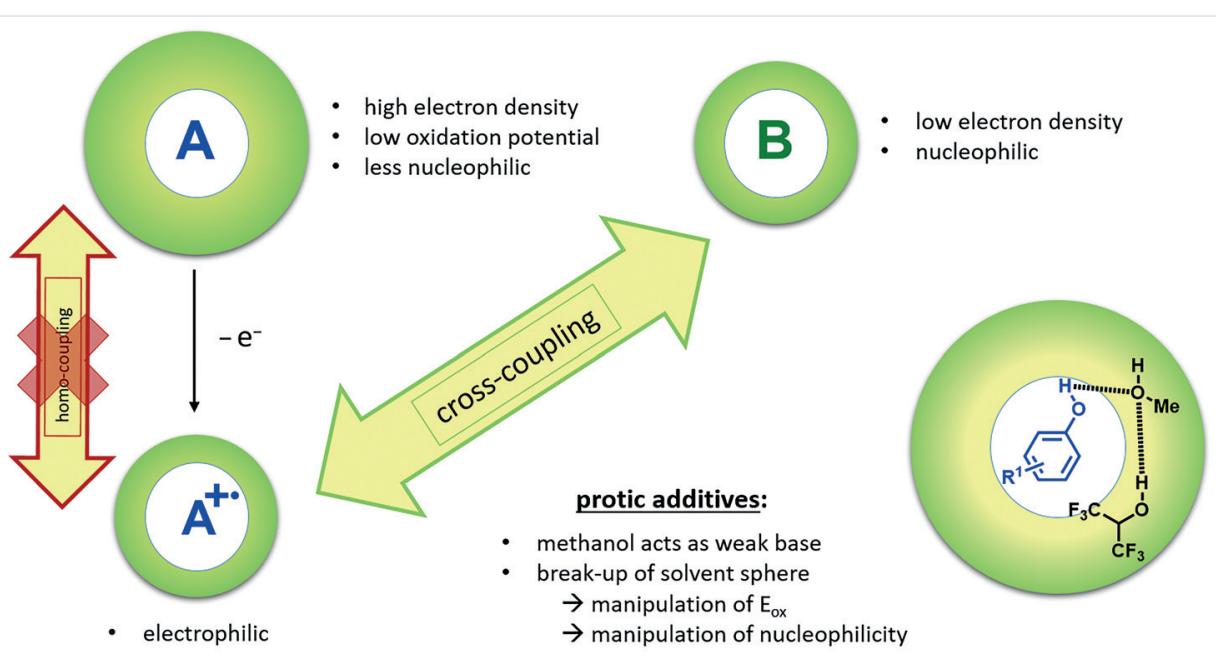

Scheme 7 Source of the selectivity in anodic cross-coupling reactions of different aryls by the solvent effect of HFIP. The color indicates the density of the solvation sphere. ${ }^{30,31}$ 


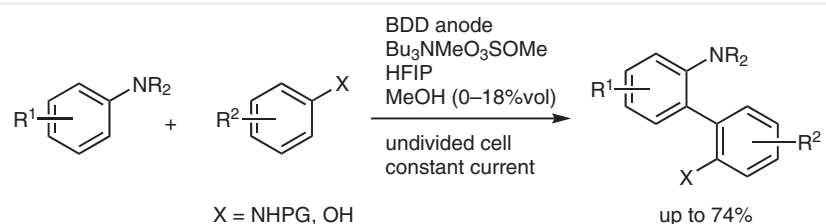<smiles>COc1cc(NC(=O)c2ccccc2)c(-c2cc(OC)c(OC)cc2NC(C)=O)cc1C</smiles><smiles>COc1cc(NC(C)=O)c(-c2cc(C)c(O)c(Cl)c2NC(C)=O)cc1OC</smiles><smiles>COc1cc(-c2cc(OC)c(I)cc2NC=O)c(NC=O)cc1I</smiles><smiles>Cc1cc(NC=O)c(-c2cc(C)c(C)cc2NC=O)cc1C</smiles>

$47 \%$<smiles>COc1cc(-c2c(NC(C)c3ccccc3)ccc3ccccc23)c(O)c(C(C)(C)C)c1</smiles>

$48 \%$<smiles>COc1cc(OC)c2c(-c3c(N(C)C)ccc4ccccc34)c(O)ccc2c1</smiles>

$45 \%$

Scheme 8 Electrochemical synthesis of protected symmetric and nonsymmetric bianiline derivatives (middle row) and synthesis of N,O-biaryl structures by coupling of naphthylamines with phenols (bottom row) ${ }^{36,37,41}$

m-terphenyl-2,2"-diols:

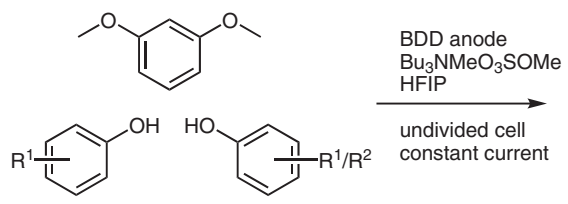<smiles>[R17]c1ccc(-c2cc(C3=C(O)C=C[R1]([H])C=C3)c(OC)cc2OC)cc1</smiles>

up to $84 \%$

single and two-fold C-C-coupling of phenols with thiophenes:

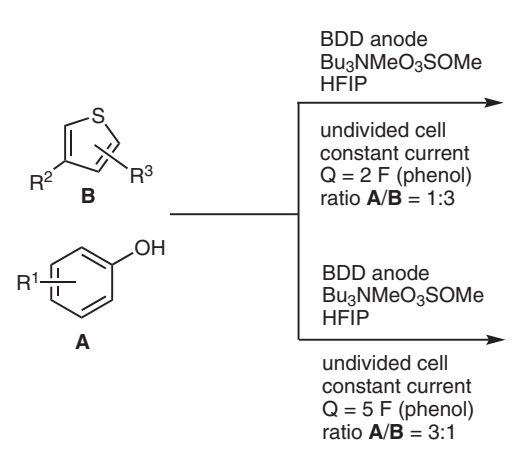<smiles></smiles>

up to $60 \%$

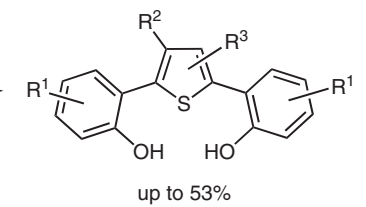

benzofurans:

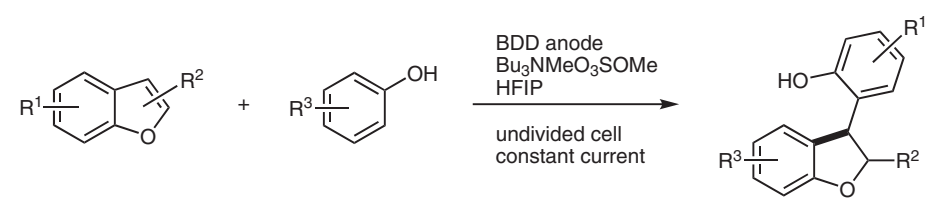

up to $61 \%$

Scheme 9 Electrochemical synthesis of symmetric and nonsymmetric m-terphenyl-2,2"-diols (upper row), single and two-fold coupling of phenols with thiophenes (middle row), and benzofuran synthesis through metathesis (bottom row). ${ }^{33,42,43}$ 
<smiles>COc1cc(-c2cc(-c3cc(OC)c(C(C)(C)C)cc3OC)c(OC)cc2-c2cc(OC)c(O)c(-c3c(O)ccc4ccccc34)c2O)c(O)c(C(C)(C)C)c1</smiles>

Figure 8 Comparison of $\mathrm{C}-\mathrm{C}$ cross-coupling reactions at different current densities $\left(j=7.2 \mathrm{~mA} / \mathrm{cm}^{2}\right.$ and $\left.35 \mathrm{~mA} / \mathrm{cm}^{2}\right)$

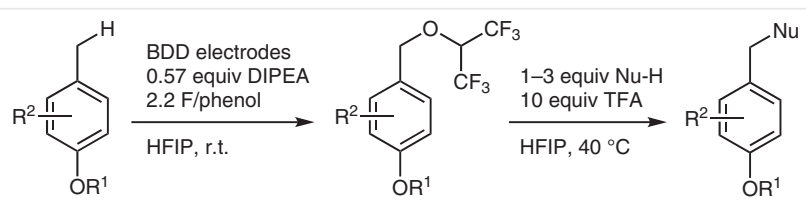
$58-99 \%$ $24-93 \%$<smiles>COc1cc(OC)c(OC)cc1Cc1cc(C)c(O)c(C)c1</smiles>
$93 \%$<smiles>COc1cc(Cc2sccc2Br)ccc1O</smiles><smiles>Cc1cc(Cc2c(C)c3cc(O)ccc3oc2=O)cc(C)c1O</smiles>

Scheme 10 Anodic benzylic functionalization of a phenol with HFIP and subsequent coupling to a nucleophile ${ }^{45}$

Very recently, a formal benzyl-aryl cross-coupling through an electro-generated masked benzylic cation was reported. In this conversion HFIP acts, despite its low nucleophilicity, as a nucleophile to form HFIP ethers. This method can also be used for late-stage functionalization of natural products and biologically active compounds (Scheme 10). ${ }^{45}$

Another emphasis of the Waldvogel group exists in the intramolecular $\mathrm{N}-\mathrm{N}$ coupling through anodically generated amidyl radicals to form pyrazolidin-3,5-diones and phthalazin-1,4-diones. ${ }^{46,47,49}$ These electro-conversions of malonic acid dianilides were only feasible in HFIP; other solvents failed or only gave traces of the desired compounds. This again underlines the exceptional, radical-stabilizing properties of HFIP. If the $\mathrm{N}-\mathrm{N}$ bond formation of dianilides proceeds too slowly, a competing $\mathrm{C}-\mathrm{O}$ bond formation takes place, resulting in benzoxazoles (Scheme 11). ${ }^{48}$

\section{Conclusion}

The control of the reaction pathway by suitable solvents is an efficient and effective strategy. This has been demonstrated in anodic conversions on prep-scale electrosyntheses. One of the most powerful methods implies the use of
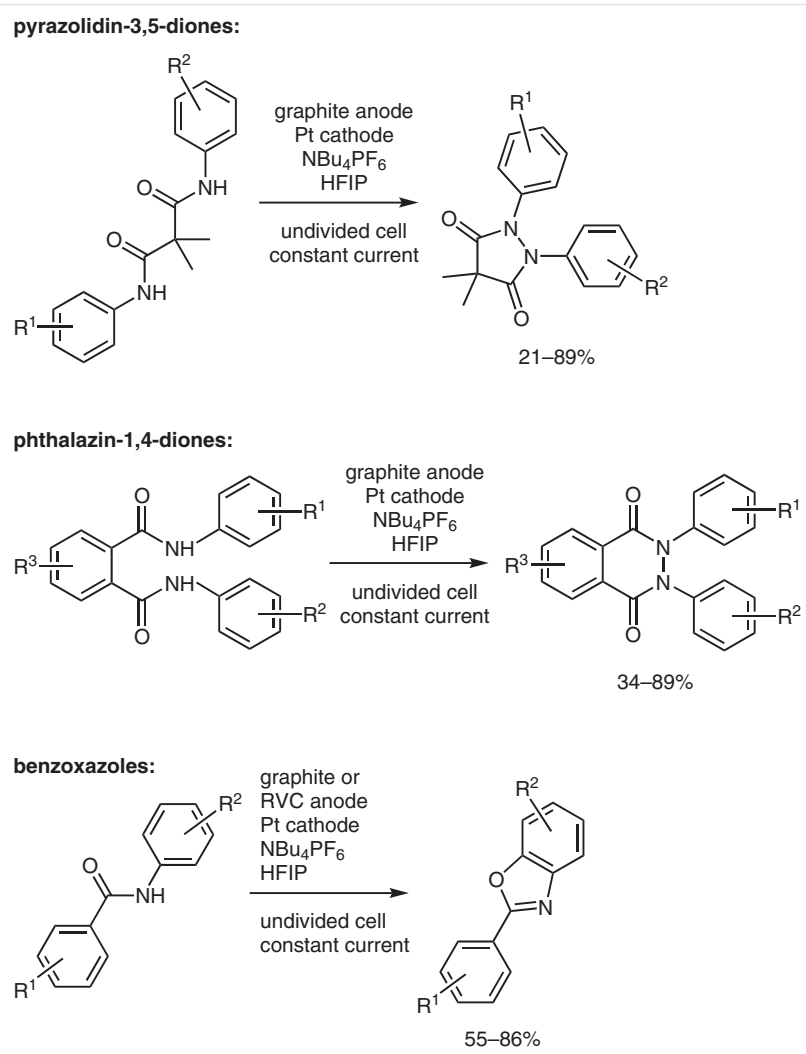

Scheme 11 Anodic synthesis of pyrazolidin-3,5-diones and phthalazin1,4-diones and benzoxazoles through intramolecular coupling in HFIP. ${ }^{46-49}$

1,1,1,3,3,3-hexafluoropropan-2-ol (HFIP) as the solvent for electrolytes. This particular medium can modulate the nucleophilicity of the substrates and is able to stabilize intermediates as well as the final product from over-oxidation. This concept and electrolytic approach will be inevitable for future electro-synthetic applications.

\section{Funding Information}

S.R.W thanks the DFG Wa1276/17-1 for financial support. The authors highly appreciate the financial support by the Center for INnovative and Emerging MAterials (CINEMA) and the support by BMBFEPSYLON (FKZ 13XP5016D).

\section{References}

(1) (a) Fuchigami, T.; Atobe, M.; Inagi, S. Fundamentals and Applications of Organic Electrochemistry. Synthesis Materials Devices; John Wiley \& Sons: Chichester, 2015. (b) Möhle, S.; Zirbes, M.; Rodrigo, E.; Gieshoff, T.; Wiebe, A.; Waldvogel, S. R. Angew. Chem. Int. Ed. 2018, 57, 6018.

(2) Wiebe, A.; Gieshoff, T.; Möhle, S.; Rodrigo, E.; Zirbes, M.; Waldvogel, S. R. Angew. Chem. Int. Ed. 2018, 57, 5594.

(3) Grimshaw, J. Electrochemical Reactions and Mechanisms in Organic Chemistry; Elsevier: Amsterdam and New York, 2000. 
(4) Organic Electrochemistry; Hammerich, O.; Speiser, B., Ed.; CRC Press: Boca Raton, 2016.

(5) (a) Chiba, K.; Kim, S. Electrochemistry 2009, 77, 21. (b) Shoji, T.; Haraya, S.; Kim, S.; Chiba, K. Electrochim. Acta 2016, 200, 290.

(6) Heinze, J.; Steckhan, E. Top. Curr. Chem; Springer: Berlin, 1990, Vol. 152.

(7) Fuchigami, T.; Inagi, S. Chem. Commun. 2011, 47, 10211.

(8) Renaud, R. N.; Sullivan, D. E. Can. J. Chem. 1973, 51, 772.

(9) Kimura, K.; Horie, S.; Minato, I.; Odaira, Y. Chem. Lett. 1973, 2, 1209.

(10) (a) Rozhkov, I. N. Russ. Chem. Rev. 1976, 45, 615. (b) Laurent, E.; Marquet, B.; Tardivel, R.; Thiebault, H. Tetrahedron Lett. 1987, 28,2359

(11) (a) Meurs, J. H. H.; Eilenberg, W. Tetrahedron 1991, 47, 705. (b) Lee, S. M.; Roseman, J. M.; Blair Zartman, C.; Morrison, E. P.; Harrison, S. J.; Stankiewicz, C. A.; Middleton, W. J. J. Fluorine Chem. 1996, 77, 65. (c) Suryanarayanan, V.; Noel, M. J. Fluorine Chem. 1998, 92, 177.

(12) Hasegawa, M.; Ishii, H.; Fuchigami, T. Green Chem. 2003, 5, 512.

(13) (a) Eberson, L.; Hartshorn, M. P.; Persson, O. J. Chem. Soc., Chem. Commun. 1995, 1131. (b) Eberson, L.; Persson, O.; Hartshorn, M. P. Angew. Chem. Int. Ed. 1995, 34, 2268.

(14) Hollóczki, O.; Berkessel, A.; Mars, J.; Mezger, M.; Wiebe, A.; Waldvogel, S. R.; Kirchner, B. ACS Catal. 2017, 7, 1846.

(15) (a) Berkessel, A.; Adrio, J. A.; Hüttenhain, D.; Neudörfl, J. M. J. Am. Chem. Soc. 2006, 128, 8421. (b) Shuklov, I.; Dubrovina, N.; Börner, A. Synthesis 2007, 2925.

(16) Berkessel, A.; Adrio, J. A. J. Am. Chem. Soc. 2006, 128, 13412.

(17) Kirste, A.; Nieger, M.; Malkowsky, I. M.; Stecker, F.; Fischer, A.; Waldvogel, S. R. Chem. Eur. J. 2009, 15, 2273.

(18) Berkessel, A.; Vormittag, S. S.; Schlörer, N. E.; Neudörfl, J.-M. J. Org. Chem. 2012, 77, 10145.

(19) Seebach, D.; Beck, A. K.; Heckel, A. Angew. Chem. Int. Ed. 2001, $40,92$.

(20) Wagner, J. P.; Schreiner, P. R. Angew. Chem. Int. Ed. 2015, 54, 12274.

(21) Morofuji, T.; Shimizu, A.; Yoshida, J.-i. Angew. Chem. Int. Ed. 2012, 51, 7259.

(22) Malkowsky, I. M.; Rommel, C. E.; Fröhlich, R.; Griesbach, U.; Pütter, H.; Waldvogel, S. R. Chem. Eur. J. 2006, 12, 7482.

(23) (a) Malkowsky, I. M.; Rommel, C. E.; Wedeking, K.; Fröhlich, R.; Bergander, K.; Nieger, M.; Quaiser, C.; Griesbach, U.; Pütter, H.; Waldvogel, S. R. Eur. J. Org. Chem. 2006, 241. (b) Barjau, J.; Königs, P.; Kataeva, O.; Waldvogel, S. Synlett 2008, 2309. (c) Barjau, J.; Schnakenburg, G.; Waldvogel, S. R. Angew. Chem. Int. Ed. 2011, 50, 1415.

(24) Malkowsky, I. M.; Griesbach, U.; Pütter, H.; Waldvogel, S. R. Eur. J. Org. Chem. 2006, 4569.

(25) (a) Montilla, F.; Michaud, P. A.; Morallón, E.; Vázquez, J. L.; Comninellis, C. Electrochim. Acta 2002, 47, 3509. (b) Morão, A.; Lopes, A.; Pessoa de Amorim, M. T.; Gonçalves, I. C. Electrochim. Acta 2004, 49, 1587.

(26) Kirste, A.; Schnakenburg, G.; Waldvogel, S. R. Org. Lett. 2011, 13, 3126.

(27) Kirste, A.; Schnakenburg, G.; Stecker, F.; Fischer, A.; Waldvogel, S. R. Angew. Chem. Int. Ed. 2010, 49, 971.

(28) Francke, R.; Cericola, D.; Kötz, R.; Weingarth, D.; Waldvogel, S. R. Electrochim. Acta 2012, 62, 372.

(29) Colomer, I.; Chamberlain, A. E. R.; Haughey, M. B.; Donohoe, T. J. Nat. Rev. Chem. 2017, 1, 88.

(30) Kirste, A.; Elsler, B.; Schnakenburg, G.; Waldvogel, S. R. J. Am. Chem. Soc. 2012, 134, 3571.
(31) Elsler, B.; Wiebe, A.; Schollmeyer, D.; Dyballa, K. M.; Franke, R.; Waldvogel, S. R. Chem. Eur. J. 2015, 21, 12321.

(32) Wiebe, A.; Schollmeyer, D.; Dyballa, K. M.; Franke, R.; Waldvogel, S. R. Angew. Chem. Int. Ed. 2016, 55, 11801.

(33) Wiebe, A.; Lips, S.; Schollmeyer, D.; Franke, R.; Waldvogel, S. R. Angew. Chem. Int. Ed. 2017, 56, 14727.

(34) Selection of patents submitted by Waldvogel et al.: (a) Dyballa, K. M.; Franke, R.; Fridag, D.; Waldvogel, S. R.; Elsler, B. PCT Int. Appl. WO 2014135236 A1 20140912, Ger. Offen. 2014 DE 102013203865 A1 20140911, US Patent 9,879,353, 2014. (b) Dyballa, K. M.; Franke, R.; Fridag, D.; Waldvogel, S. R.; Elsler, B. PCT Int. Appl. WO 2014135405 A1 20140912, Ger. Offen. 2014 DE 102013203867 A1 20140911, 2014. (c) Dyballa, K. M.; Franke, R.; Fridag, D.; Waldvogel, S. R.; Elsler, B. PCT Int. Appl WO 2014135237 A1 20140912, Ger. Offen. DE 102013203866 A1 20140911, 2014. (d) Dyballa, K. M.; Franke, R.; Fridag, D.; Waldvogel, S. R.; Elsler, B.; Enders, M. PCT Int. Appl , WO 2016034332 A1 20160310, 2016. (e) Dyballa, K. M.; Franke, R.; Fridag, D.; Waldvogel, S. R.; Elsler, B.; Enders, M. PCT Int. Appl WO 2016034330 A1 20160310, 2016. (f) Dyballa, K. M.; Franke, R.; Fridag, D.; Waldvogel, S. R.; Elsler, B.; Enders, M. PCT Int. Appl WO 2016034327, 2016. (g) Dyballa, K. M.; Franke, R.; Fridag, D.; Waldvogel, S. R.; Elsler, B.; Enders, M. PCT Int. Appl WO 2016034328 A1 20160310, 2016. (h) Dyballa, K. M.; Franke, R.; Fridag, D.; Waldvogel, S. R.; Elsler, B.; Wiebe, A. Ger. Offen DE 102015207280 A1 20160303, 2016. (i) Dyballa, K. M.; Franke, R.; Fridag, D.; Waldvogel, S. R.; Elsler, B.; Enders, M. Ger. Offen. DE 102014217537 A1 20160303, 2016. (j) Dyballa, K. M.; Franke, R.; Fridag, D.; Waldvogel, S. R.; Elsler, B.; Wiebe, A. Eur. Pat. Appl EP 3133054 A1 20170222, 2017. (k) Dyballa, K. M.; Franke, R.; Fridag, D.; Waldvogel, S. R.; Elsler, B.; Wiebe, A. Ger. Offen DE 102015215995 A1 20170223, 2017. (l) Dyballa, K. M.; Franke, R.; Fridag, D.; Waldvogel, S. R.; Elsler, B.; Wiebe, A. Ger. Offen. DE 102015215997 A1 20170223, 2017. (m) Dyballa, K. M.; Franke, R.; Fridag, D.; Waldvogel, S. R.; Elsler, B.; Wiebe, A. Ger. Offen DE 102015215998 A1 20170223, 2017. (n) Dyballa, K. M.; Franke, R.; Fridag, D.; Waldvogel, S. R.; Elsler, B.; Wiebe, A.; Lips, S. Eur. Pat. Appl. EP 3133189 A1 20170222, 2017. (o) Dyballa, K. M.; Franke, R.; Fridag, D.; Dahms, B.; Waldvogel, S. R. Eur. Pat. Appl EP 3252033 A1 20171206, 2017. (p) Waldvogel, S. R.; Dahms, B.; Franke, R. Eur. Pat. Appl. EP 17203772.3, 2018. (q) Waldvogel, S. R.; Frontana-Uribe, B. A.; Wiebe, A.; Lips, S.; Franke, R. Eur. Pat. Appl EP 17203773.1, 2018.

(35) Riehl, B.; Dyballa, K.; Franke, R.; Waldvogel, S. Synthesis 2016, 49, 252.

(36) Schulz, L.; Enders, M.; Elsler, B.; Schollmeyer, D.; Dyballa, K. M.; Franke, R.; Waldvogel, S. R. Angew. Chem. Int. Ed. 2017, 56, 4877.

(37) Schulz, L.; Franke, R.; Waldvogel, S. R. ChemElectroChem 2018, 5, 2069.

(38) Mohilner, D. M.; Adams, R. N.; Argersinger, W. J. J. Am. Chem. Soc. 1962, 84, 3618

(39) Elsler, B.; Schollmeyer, D.; Dyballa, K. M.; Franke, R.; Waldvogel, S. R. Angew. Chem. Int. Ed. 2014, 53, 5210.

(40) Wiebe, A.; Riehl, B.; Lips, S.; Franke, R.; Waldvogel, S. R. Science Advances 2017, 3, eaao3920/1.

(41) Dahms, B.; Franke, R.; Waldvogel, S. R. ChemElectroChem 2018, 5,1249

(42) Lips, S.; Wiebe, A.; Elsler, B.; Schollmeyer, D.; Dyballa, K. M.; Franke, R.; Waldvogel, S. R. Angew. Chem. Int. Ed. 2016, 55, 10872.

(43) Lips, S.; Frontana-Uribe, B. A.; Dörr, M.; Schollmeyer, D.; Franke, R.; Waldvogel, S. R. Chem. Eur. J. 2018, 24, 6057. 
(44) Lips, S.; Schollmeyer, D.; Franke, R.; Waldvogel, S. R. Angew. Chem. Int. Ed. 2018, 57, 13325.

(45) Imada, Y.; Röckl, J. L.; Wiebe, A.; Gieshoff, T.; Schollmeyer, D.; Chiba, K.; Franke, R.; Waldvogel, S. R. Angew. Chem. Int. Ed. 2018, 57, 12136.

(46) Gieshoff, T.; Schollmeyer, D.; Waldvogel, S. R. Angew. Chem. Int. Ed. 2016, 55, 9437.
(47) Kehl, A.; Gieshoff, T.; Schollmeyer, D.; Waldvogel, S. R. Chem. Eur. J. 2018, 24, 590.

(48) Gieshoff, T.; Kehl, A.; Schollmeyer, D.; Moeller, K. D.; Waldvogel, S. R. Chem. Commun. 2017, 53, 2974.

(49) Gieshoff, T.; Kehl, A.; Schollmeyer, D.; Moeller, K. D.; Waldvogel, S. R. J. Am. Chem. Soc. 2017, 139, 12317. 